\title{
DEBATE SOBRE SILENCIO DEL IMPUTADO.
}

\author{
CRISTIAN RIEGO ${ }^{1}$.
}

\section{Resumen.}

El artículo aborda la cuestión de la posibilidad de utilizar el silencio del imputado como prueba en su contra en el proceso penal chileno. En primer lugar se discute la tesis planteada por varios autores en el sentido que el reconocimiento del derecho a guardar silencio por parte del imputado excluiría la posibilidad de utilizar ese mismo silencio para extraer en su contra inferencia inculpatorias. El texto plantea que desde el punto de vista teórico, de derecho comparado y de derecho internacional se trata de una cuestión debatida que puede ser resuelta por la ley nacional. Finalmente, el autor sostiene que una correcta interpretación de la ley chilena no solo permite el uso del silencio del imputado como elemento de prueba en contra del imputado, sino que el juez en la sentencia debe siempre analizar su significado con el fin de evitar un uso abusivo del mismo.

\section{Palabras clave:}

Proceso penal - derecho a guardar silencio - prueba.

\begin{abstract}
.
The paper discusses the posibility of extract inferences against de defendant from his silence. First it confronts the opinions that the right to remain silent in incompatible with any use of the same silence to extract inferences against the defendant. According the author the issue is disputed in legal theory, in the international law of Humans Rigths and in comparative law. Finaly the text argues that according a correct interpretation of the chilean law of criminal procedure the use of the defendant's silence against
\end{abstract}

$\overline{1}$ Profesor de Derecho Procesal, Universidad Diego Portales. cristian.riego@udp.cl. 
himself is no only allowed, but is required that the judge analices its meaning in the decision to avoid an abussive use of it.

\section{Key Words:}

Criminal procedure - right to remain silent - evidence.

\section{Introducción.}

En un artículo de reciente publicación el profesor Carlos Correa realiza una interesante descripción sobre como se ha resuelto la cuestión de la valoración del silencio del imputado en Alemania. ${ }^{2}$ Paralelamente el artículo plantea la opinión del autor acerca de cómo debiera resolverse esa misma cuestión de acuerdo con la ley chilena.

El presente trabajo tiene el propósito de discutir el planteamiento del profesor Correa en cuanto a su interpretación de la ley chilena y plantear una interpretación alternativa, todo con el objetivo de profundizar sobre una cuestión probatoria que es muy importante en la práctica de nuestros tribunales y en las consideraciones estratégicas de fiscales y defensores pero que no suele ser objeto de mayores análisis en nuestra literatura.

Para ordenar la presentación intentaré hacerme cargo de los que me parece son los tres planteamientos principales del profesor Correa los que espero poder sintetizar de manera fiel.

El primer planteamiento, es que el reconocimiento del silencio del imputado como un derecho por parte de nuestra ley y por normas supralegales como son diversos tratados internacionales de derechos humanos, impide que se pueda atribuir valor probatorio a ese mismo silencio. Sostendremos que no hay incompatibilidad entre el reconocimiento del derecho al silencio y la valoración del mismo en la sentencia penal.

El segundo planteamiento, es que el silencio del imputado en una etapa del proceso penal o en un momento de una declaración, impide la utilización de ese silencio como elemento que permita valorar la declaración prestada por el imputado en otra etapa del mismo proceso o en otro momento. El

2 CORREA, Carlos: "Valoración del silencio del imputado en el proceso penal. Derecho alemán y derecho chileno". En: Revista de Derecho, [S.1.], v. 31, n. 2, p. 237-261, oct. 2018. ISSN 0718-0950. Disponible en: <http://revistas.uach.cl/index.php/ revider/article/view/3813>. Fecha de acceso: 10 may 2019: https://doi.org/10.4067/S071809502018000200237. 
profesor Correa se refiere a esto como la valoración del silencio temporal y parcial, que es la formulación alemana del problema. Frente a esto, nuestro punto de vista es que el silencio en una etapa o momento del procedimiento es un elemento ineludible para valorar declaraciones prestadas por el imputado en una etapa o momento diferente y está exigido por nuestra ley probatoria.

La tercera idea planteada por el profesor Correa requiere una mayor explicación para ser formulada. El profesor Correa plantea que la norma introducida por la ley $\mathrm{N}^{\mathrm{o}} 20.592$ de 2012, que modificó la redacción de la letra h) del artículo 93 del Código Procesal Penal, estableció una prohibición general de la valoración del silencio del imputado. La norma en cuestión forma parte de las advertencias que la policía y el Ministerio Público deben hacer al imputado antes de que éste preste su primera declaración ante ellos. La reforma legal agregó que la advertencia debe incluir, además, que tiene derecho a guardar silencio, la indicación de que lo que el imputado diga puede ser usado en su contra y que su silencio no tendrá consecuencias legales posteriores.

A pesar de que el sentido de esa norma nos parece equívoco, ${ }^{3}$ tendemos a coincidir que se debe interpretar como una prohibición de valoración del silencio del imputado y en ese sentido estamos de acuerdo con el profesor Correa. No obstante, no estamos de acuerdo con entender esa prohibición como una de carácter general, esto es aplicable a todas las ocasiones en que el imputado tiene la posibilidad de optar por el silencio en el proceso penal. Creemos, en cambio, que la norma solo implica una prohibición de valorar el silencio que el imputado ha mantenido en las dos ocasiones específicas mencionadas en la norma, esto en las primeras declaraciones prestadas frente a la policía o al fiscal. En nuestra opinión, y esto es lo que trataremos de fundamentar con detalle, la regla en cuestión no prohibe otrorgar valor probatorio al silencio del imputado cuando este se produce

3 En nuestra tradición legal, hasta hace relativamente poco tiempo se entendía que el silencio podía tener consecuencias legales desfavorables para el imputado que no se referían a su valoración como prueba. El artículo 327 del antiguo Código de Procedimiento Penal obligaba al juez a advertir al imputado que su silencio podía privarlo de medios de defensa. Por otra parte, la práctica de los tribunales hacía que el imputado se viera obligado a colaborar dando su versión de los hechos al juez, dado que, de no hacerlo, el juez podía tomar en su contra medidas como la detención hasta por cinco días, la prisión preventiva y, sobre todo, la incomunicación también hasta por cinco días renovables por otro periodo igual. En el contexto planteado, creo que la regla podría también interpretarse en el sentido de dejarle claro al imputado de que su silencio no le significará medidas de apremio o privación de otros derechos. 
en otras ocasiones, por ejemplo, en el juicio ante el juez de garantía, o ante el propio fiscal en otras etapas de la investigación.

\section{El silencio del imputado como derecho.}

El profesor Correa plantea que el reconocimiento del silencio del imputado como derecho impediría su valoración como prueba. Para esto se basa fundamentalmente en la jurisprudencia constitucional y la doctrina mayoritaria alemana, que entienden que existe una completa incompatibilidad entre ambas cuestiones, a lo menos, en cuanto al silencio total, esto es, cuando el imputado no declara en ninguna de las etapas del proceso en las que puede hacerlo. Para fundamentar la conclusión expuesta se plantean argumentos tanto normativos como prácticos. A partir de esos razonamientos, el profesor Correa plantea que la existencia en nuestra ley, como en tratados internacionales que son obligatorios para Chile, del reconocimiento del derecho a no declarar, debiera llevarnos a una conclusión semejante a la que se ha asentado en Alemania, en el sentido de entender que no está permitido atribuir ningún valor al silencio del imputado en el proceso penal.

Los argumentos que según Correa ha dado la doctrina alemana, dicen relación, en primer lugar, con que el reconocimiento del derecho a no declarar supone que este se ejerza libre de toda presión, ${ }^{4}$ y que la amenaza del uso del silencio en contra del imputado generaría una verdadera obligación de declarar. ${ }^{5}$ Además y desde una perspectiva práctica se plantea la imposibilidad de otorgar un sentido univoco al silencio dada la falta de acceso a los motivos que pudiera tener el imputado para mantenerlo. ${ }^{6}$

En el caso de la ley chilena, el profesor Correa plantea, además, la existencia de una prohibición explícita de valoración del silencio, pero esa discusión la abordaremos más adelante.

Pero vamos a la cuestión de la compatibilidad del reconocimiento del derecho a no declarar con la valoración del silencio. Lo primero, es plantear que si bien en Alemania se entiende que existe esa incompatibilidad, eso no es así en otras jurisdicciones que también están entre las más prestigiosas en cuanto al desarrollo dogmático y la vigencia de las garantías. Probablemente el caso más notorio es el del Reino Unido, donde la ley

\footnotetext{
$4 \quad$ CORREA, ob cit. Pág. 243.

5 Ibíd. Pág. 244.

6 Ibíd. Pág. 245.
} 
reconoce explicítamente la posibilidad de que el silencio del imputado sea valorado e, incluso, indica con detalle cuáles son las situaciones específicas que pueden dar lugar a esa valoración. ${ }^{78}$

Pero es claro que esta cuestión no es unánime en los países anglosajones, en los Estados Unidos, en el año 1965, la Corte Suprema, por medio del caso Griffin vs California, estableció el criterio de que ni el fiscal ni el juez pueden plantear al jurado inferencias negativas derivadas del silencio del acusado. ${ }^{9}$ Esto es, la cuestión no se plantea como una prohibición de valoración, dado que en el sistema del jurado la valoración de la prueba por parte del jurado no es objeto de control, si no que como una prohibición de plantear ante el jurado una cierta interpretación del silencio del imputado que pudiere resultar perjudicial para su caso, y que el jurado pudiese considerar en su análisis de la prueba.

Pero tampoco es unánime la cuestión en los países de la tradición de Europa Continental, concretamente, en el caso español, a pesar de que alguna doctrina se alínea con la posición sostenida por profesor Correa, la jurisprudencia ha sostenido en numerosos fallos que bajo ciertas condiciones la valoración del silencio del imputado en el fallo no resulta contraria a las garantías básicas. ${ }^{10}$

Por su parte el Tribunal Europeo de Derechos Humanos ha tenido en diversas ocasiones la oportunidad de pronunciarse acerca de la cuestión de la valoración del silencio, fundamentalmente en relación con los casos derivados de la regulación británica. El criterio de la Corte Europea ha sido que la sola posibilidad de la valoración del silencio no es en sí misma contraria a la Convención Europea y al derecho a guardar silencio contenido en ella.

$7 \quad$ Sección 34 Criminal Justice and Public Order Act 1994.

8 Sobre el proceso de introducción de esa legislación en el Reino Unido. O'REILLY, Gregory: "Limits the Rigth to Silence and Moves Towards an Inquisitorial System of Justice". En: Journal of Criminal Law and Criminology, Volume 85, Issue 2, 1994. Págs. 402-452.

9 AYER, Donald: "The Fifth Amendment and the Inference of guilt form silence: Griffin v California after Fifteen Years”. En: Michigan Law Review, Vol 78, № 6 (may, 1980). Págs. 841-871.

10 ASCENCIO, Jose María: "El derecho al silencio del imputado". En: Revista Digital de la Maestría en Ciencias Penales, Número 9. Año 9, 2017. También MORALES, Oscar: "El poder de las costumbres ¿requiem por el derecho a guardar silencio?". En: Actualidad Jurídica Uria Mendez, №36, 2014. Págs. 53-67. 
El fallo del Tribunal Europeo que ha establecido el criterio para examinar esa compatibilidad, es el recaído sobre el caso Murray ${ }^{11}$ ocurrido en Irlanda del Norte. Se trató de una persona condenada por haber secuestrado a un miembro de IRA que colaboraba con la policía. La policía irrumpió en el lugar donde se encontraba el secuestrado y arrestó al acusado que guardó silencio. En el juicio, la víctima declaró que durante su captura fue obligado a confesar y su confesión fue grabada, también dijo que cuando la policía arribó al lugar, pudo ver al acusado y este le ordenó que simulara ver televisión. Además, indicó haber visto al acusado manipulando una grabadora tratando de sacar la cinta, la que fue encontrada en otro lugar de la casa con una cinta que contenía la confesión del informante.

El acusado guardó también silencio durante el juicio y el juez que conoció el caso consideró que, dadas las circunstancias del caso, resulta de sentido común extraer inferencias contrarias al acusado a partir de su silencio.

El Tribunal resolvió que el derecho a guardar silencio no es un derecho absoluto y que su compatibilidad con la posibilidad de hacer inferencias negativas del mismo no debe resolverse de modo abstracto, sino que en consideración a las circunstancias específicas del caso. En la situación descrita, el tribunal considera que se trata de un caso suficientemente sólido como para requerir una respuesta por parte del imputado y esta expectativa no supone una presión indebida a declarar, ni una alteración de la carga de la prueba contraria a la presunción de inocencia.

La postura del Tribunal Europeo de Derechos Humanos nos parece que esclarece muy bien una cuestión que puede prestarse a confusión, esta es el claro rechazo a la idea de utilizar el silencio para hacer inferencias abusivas, que no se deducen realmente del mismo, y que alteran la carga de la prueba, distinguiéndola de otra situación en la cual el silencio adquiere cierta elocuencia y donde resulta lícito hacer algunas inferencias.

El fallo del Tribunal Europeo deja claro que es contrario a las garantías básicas usar el silencio para dar por probados hechos respecto de los cuales no existe prueba, o en que ésta es precaria. Esta pretensión violenta la presunción de inocencia, en cuanto altera la carga de la prueba y el propio derecho a guardar silencio, puesto que, le impone un costo excesivo.

En situaciones de debilidad de la prueba de cargo, el silencio del imputado es totalmente ambiguo en su significado y sería abusivo de deducir nada 
de él. Frente a una prueba insuficiente, el razonamiento del imputado que guarda silencio podría ser el de preferir que el juzgador aprecie la debilidad de la prueba del fiscal y no correr el riesgo de, eventualmente, fortalecerla mediante una declaración que puede evidenciar contradicciones $\mathrm{u}$ otros problemas. Por lo tanto, deducir automáticamente del silencio un indicio de culpabilidad es un exceso y puede representar una vuelta a la lógica de un sistema inquisitivo arcaico, donde el derecho al silencio no tenía reconocimiento.

En cambio, una situación muy distinta se produce cuando se trata de hechos en que la prueba de cargos adquiere una solidez tal, que "se pone al imputado en la situación de tener que dar una explicación si la hubiese”. Es decir, en la medida que la prueba adquiere fuerza, el silencio del imputado pierde la ambigüedad a la que nos hemos referido recién. En un caso sólido, en el que la prueba muestra que los hechos deben haber ocurrido según la versión planteada por el fiscal, si hubiese una explicación alternativa parece lógico que el imputado tendría que darla y carece por completo de sentido que éste adopte una posición completamente pasiva, dado que la idea de "mejor no hablo para no correr el riesgo de fortalecer el débil caso del fiscal", carece de sentido. Solo en este tipo de situaciones, valorar el silencio no es un abuso, sino que una inferencia apropiada que no vulnera la presunción de inocencia, ni impone costos exesivos al ejercicio del derechos al silencio.

Como se puede ver, es posible distinguir con alguna claridad dos situaciones diferentes, una consistente con las garantías y la otra no. No obstante, resulta también claro que en los casos de valoración del silencio que estarían admitidos, su aporte probatorio es bien limitado, puesto que, se trata de casos con prueba sólida que incluso podrían prescindir del silencio.

En general, la noción que rechaza la valoración del silencio supone que éste, en tanto derecho, no debe tener costo alguno para quien lo ejercita. Esta postura no parece razonable, debido a que el ejercicio de la autonomía individual, de la cual el derecho a declarar o a guardar silencio en un proceso penal son expresiones específicas, siempre presenta como contracara el efecto de hacerse cargo de las consecuencias. Existen innumerables ejemplos de lo anterior y el más claro es el de la declaración; declarar es un derecho y quien lo ejercita se hace cargo de las posibles consecuencias negativas. El punto no es, entonces, que el ejercicio del derecho acarree consecuencias negativas, sino si estas resultan razonables o excesivas, de modo que pueden terminar anulando el derecho en cuestión. El propio 
fallo Murray ha ponderado apropiadamente esta cuestión, estableciendo un criterio para limitar las consecuencias probatorias que se pueden extraer del silencio del imputado para que ellas sean consistentes con el derecho a guardar silencio y con la presunción de inocencia.

Pero tampoco existe unanimidad sobre esto en el derecho internacional. El estatuto de Roma que regula a la Corte Penal Internacional, se inclina en sentido contrario al expuesto, prohibiendo en dos ocasiones la valoración del silencio del imputado, una referida al periodo de investigación y la otra al juicio. ${ }^{12}$

Nos parece que esta rápida revisión del derecho comparado, de lo que da cuenta es de que no existe una postura consolidada en el sentido de una contradicción entre normas básicas del debido proceso y la posibilidad de otorgarle a este algún valor probatorio. Se trata, en cambio, de una cuestión debatida en la que las diversas legislaciones nacionales y culturas legales deben encontrar soluciones apropiadas, con el límite de ser consistentes con el conjunto de las demás garantías. Dicho de otro modo, la proclamación del derecho a guardar silencio no resuelve por sí mismo la cuestion de la valoración del silencio del imputado, ni a nivel legal, ni a partir de normas supralegales, solo fija un límite a ciertas formas de valoración del silencio que son claramente contrarias a las garantías básicas.

\section{EI silencio parcial o temporal.}

Es muy común que en los procedimientos judiciales la actitud del imputado frente a su derecho a declarar, varíe de una etapa procesal a otra. Así, por ejemplo, suele ocurrir que el imputado haga declaraciones ante la policía antes de recibir asesoría de un abogado, y luego de recibir el consejo de éste decida guardar silencio en el resto del proceso y, especialmente, en el juicio. Es muy probable que el fiscal pretenda introducir el contenido de esas declaraciones en el juicio, ya sea por su contenido autoinculpatorio, o porque de algún otro modo benefician su caso. También ocurre que un imputado guarda silencio durante todo el proceso, pero decide declarar en el juicio entregando una versión que lo favorece y respecto de la cual espera ser creído. Por último, también puede ocurrir, aunque es menos frecuente, que un imputado que se encuentra declarando decida no responder a determinadas preguntas. En todos estos casos, es bastante evidente que los jueces deben, en sus sentencias, valorar la credibilidad de lo que el 
imputado ha declararado, sea para atribuirle algún valor probatorio a sus dichos, sea para descartarlos, sea que estos perjudiquen al imputado, lo cual será normal en el primer ejemplo, o sea que lo benefician, típicamente en el segundo.

De acuerdo con el sistema probatorio establecido en nuestra ley, los jueces que han de valorar la prueba presentada en juicio deben hacer un análisis racional de la misma de acuerdo con el sistema de la sana crítica, ${ }^{13}$ esto es, para valorar una declaración del imputado es necesario tener en cuenta todos los elementos de información que sirvan para comprender el sentido de sus dichos y evaluar su correspondencia con la realidad. Entre estos elementos suelen encontrarse el conjunto de las actitudes que el imputado ha tenido, entre las que pueden estar presentes sus silencios en determinados momentos.

En situaciones como las descritas, esto es, cuando existe una declaración del imputado que es necesario valorar racionalmente, parece bastante ineludible hacerse cargo de la consistencia de la misma, con otras actitudes de la persona que la formula, de la oportunidad en que se realizó $\mathrm{y}$, en general, del conjunto de su comportamiento en el proceso. Estos elementos contextualizan lo que una persona dice y son indispensables para atribuirle sentido a sus dichos, para evaluar su sinceridad y su apego a la realidad. El silencio del imputado en un momento importante puede jugar un rol fundamental para la evaluación de lo que el imputado dice en otro momento.

Imaginemos una situación en que el imputado prestó una declaración autoinculpatoria ante la policía y luego guardó silencio hasta el final del juicio. En el caso de que dicha declaración inicial resulte admisible en el juicio y deba ser valorada, ¿pueden los jueces al valorarla, prescindir de la la falta de explicaciones de parte del imputado en cuanto a los motivos para haber dicho lo que se le atribuye haber declarado inicialmente? En el otro caso que hemos usado como ejemplo, ¿si el imputado declara en el juicio y entrega una versión que lo exonera de toda participación, no deben los jueces analizar, para acoger o descartar como indicador de credibilidad, el hecho de que el imputado solo entregó su versión en el juicio y no la invocó en las etapas anteriores del proceso?

El criterio planteado, quizás se expresa de manera más radical en la situación en que el silencio se manifiesta al interior de una declaración 
del imputado en juicio. Esto es, supongamos que el imputado toma el estrado, plantea una versión favorable a su defensa, pero luego, contrainterrogado por el fiscal o frente a preguntas aclaratorias del juez, se niega a contestar alguna de ellas alegando su derecho a no declarar. La pregunta es si es posible valorar racionalmente la declaración del imputado, sin analizar el sentido de la negativa a declarar en una o más preguntas. Nos parece evidente que la respuesta es negativa. No en el sentido en que ese silencio conduzca automática y necesariamente a quitar toda credibilidad a la declaración prestada. Por el contrario, sea que se le atribuya o no credibilidad a la declaración, pareciera necesario que el sentenciador explique las razones para hacerlo o no hacerlo, analizando este elemento contextual, el silencio, acogiéndolo o descartándolo como indicador de credibilidad.

No estamos, en ningún caso, planteando que en ejemplos como los planteados el silencio parcial del imputado deba llevar necesariamente a la conclusión de atribuir mérito a la declaración policial, o restar mérito a la declaración en juicio. Muy lejos de eso, lo que pretendemos afirmar es que el silencio debe ser objeto de análisis y bien podrá resultar que, a pesar del mismo, los jueces consideren que la declaración inicial no debe ser creída, o que debe ser creída la declaración en el juicio, todo dependerá del conjunto de circunstancias del caso, del resto de las pruebas, de las versiones en juego y de los argumentos de los abogados. Lo que afirmamos es solo que el valor del silencio parcial del imputado, no puede ser excluido a priori sin renunciar a la posibilidad de una valoración racional de la prueba constituida por la declaración del imputado que se debe valorar.

De acuerdo con el texto del profesor Correa, la concepción alemana sobre la valoración del silencio no parece excluir que esta última pueda resultar útil para valorar una declaración que efectivamente se presta, sino que el fundamento de la prohibición de valoración estaría en el la vulneración de garantías, que son el límite a la tarea de búsqueda de la verdad. No obstante, nos parece que esta objeción aparece bien respondida por el criterio del Tribunal Europeo de Derechos Humanos, que logra distinguir valoraciones del silencio que vulneran las garantías, de otras que no lo hacen. En este caso, a esa consideración general debe sumarse la especial necesidad de usar el silencio como elemento destinado a valorar la declaración efectivamente prestada, la consecuencia de no hacerlo sería la de obligar al juez a valorar una 
prueba, la declaración efectivamente prestada, sin el rigor exigido por la ley respecto de todas las pruebas. ${ }^{14}$

Pero, además, tal como lo veremos más adelante, la pretensión de excluir esta información, el silencio, del análisis, no es realista. La prohibición de valoración podrá lograr que los jueces no se refieran en la sentencia al silencio del imputado como elemento relevante para valorar lo declarado en otro momento, pero eso solo evitará que su uso quede fuera del control del razonamiento en la sentencia y del recurso, difícilmente se podrá impedir que una cuestión tan significativa juegue un rol en la mente del juzgador que busca acercarse a la realidad de lo ocurrido, en la mayor medida posible.

La Corte Suprema ha acogido, en la práctica, la noción de la legitimidad del uso del silencio de imputado en el juicio para la valoración de una declaración anterior, aunque con un lenguaje algo ambiguo. Se trata de un caso de violación en que el imputado confesó su delito ante la policía, declaración que fue reproducida por los agentes ante el tribunal y que la propia Corte consideró legítima. La Corte rechazó la solicitud de nulidad contra el fallo en el que se invocaba en favor de la condena el hecho de que el imputado guardara silencio en el juicio, sin dar explicación alguna de su anterior declaración policial. La Corte consideró que la alusión al silencio por parte del juzgador, fue un elemento adicional o colateral a la abundante evidencia presentada en su contra y, por lo tanto, no constituyó el uso del silencio del imputado como un medio de prueba sobre el conflicto central. ${ }^{15}$ Pensamos que la Corte acertó en la decisión, pero erró en el lenguaje, puesto que, no distinguió apropiadamente entre pruebas sobre el hecho y pruebas que recaen sobre otras pruebas, en el caso en cuestión pensamos que el silencio no es una cuestión accesoria o colateral, sino una prueba que sirve para contextualizar y evaluar otra prueba, en este caso, la declaración policial del imputado. ${ }^{16}$

14 En los Estados Unidos esta cuestión ha sido ampliamente debatida y objeto de múltiples fallos de la Corte Suprema, los que establecen una serie de distinciones acerca de cuándo el silencio del imputado en etapas previas del proceso puede o no ser usado para cuestionar la credibilidad de su declaración en juicio. Ver ROOK SNYDER, Barbara: "A Due Process Analysis of the Impeachment Use of Silence in Criminal Trials". En: William and Mary Law Review, volume 29, issue 2, 1988. Págs. 285-340

15 Sentencia de la Corte Suprema, dictada por la Segunda Sala con fecha 20 de febrero de 2014, en causa $\mathrm{N}^{\mathrm{o}}$ 65-2014.

16 Una revisión exhaustiva de la jurisprudencia en cuanto a valoración del silencio en KUSANOVIC, Marcos: El uso del silencio del acusado en el juicio oral, su alcance y valoración en la jurisprudencia chilena. Tesis de Magíster en Derechos Penal y Procesal Penal Universidad Diego Portales, 2016. 
En un fallo más reciente, la Corte Suprema rechazó un recurso de nulidad en un caso en que el tribunal utilizó el silencio del imputado en el juicio para validar una confesión prestada ante la policía. Se trata de un caso en que una persona fue sorprendida con marihuana en la vía pública y de acuerdo con la versión de los policías, les habría indicado que era solo consumidor, que tenía más droga en su domicilio y los habría autorizado a entrar al mismo. El tribunal consideró que el silencio del imputado en el juicio hace creíble la confesión y la autorización de entrada. ${ }^{17}$

\section{El alcance de la prohibición del la letra g) del artículo 93.}

La norma de la letra g) del artículo 93 del Código Procesal Penal debe, en nuestra opinión, ser interpretada en un sentido estricto. Esto es, la prohibición legal explícita de que el silencio del imputado pueda producir consecuencias legales negativas para el mismo, entre las que se encuentra la posibilidad de hacer inferencias negativas de dicho silencio, se limita a las dos situaciones a las que se refiere precisamente la regla: la declaración ante la policia y la primera declaración ante el fiscal. En cambio, esa prohibición no se aplica a todas las otras ocasiones en que el imputado puede hablar y no lo hace. Por ejemplo, en su comparecencia ante el juez de garantía, en el juicio oral o, incluso, en otras comparecencias ante el propio fiscal, ante el cual siempre el imputado puede declarar, sea a solicitud del fiscal o por propia iniciativa.

Pensamos que el sentido de la norma y su contexto son claros, en cuanto a que lo que ella pretende es otorgar una protección especial a la autonomía del imputado en su momento de mayor vulnerabilidad, que es el de su interacción inicial con la policia y el fiscal. De hecho, la exigencia que esta norma plantea, que es la advertencia del derecho a no declarar por parte de policias y fiscales, solo rige en esas situaciones. En las comparecencias posteriores no se exige realizar la advertencia, porque el imputado está debidamente asesorado, ya conoce la imputación y, seguramente, ha tenido oportunidad de decidir cuál será su estrategia de defensa. En la situación que regula la letra g), nada de eso ha ocurrido. Además, la declaración policial es, naturalmente, un espacio de vulnerabilidad donde el imputado se encuentra solo frente a agentes dotados de autoridad, sin información de sus derechos y en una situación en la que reclamarlos resultaría altamente contraintuitivo. Por lo tanto, tiene pleno sentido dotar al imputado en esta 
situación de una protección reforzada de su autonomía, la que se traduce en la obligación de advertencia y en la prohibición de uso posterior del silencio en su contra. Además, tiene mucho sentido prohibir la valoración del silencio después de la información acerca del derecho a guardar silencio, debido a que el silencio puede tener su origen en esa misma información. El imputado que normalmente estará sin asesoría legal, bien puede entender que debe o le conviene guardar silencio y, probablemente, si es que el silencio pudiese ser valorado, debiera advertírsele tal cosa.

Es razonable pensar que si el legislador hubiese querido plantear una prohibición general de valoración del silencio del imputado, lo debiese haber hecho a propósito de su declaración que está regulada en el artículo 98, o establecerlo en una letra especial del artículo 93 como derecho, y no solo referida a la situación especial de la advertencia de derechos en la primera declaración ante el fiscal o la policía.

\section{Por qué en nuestro sistema debe permitirse y, aún, exigirse valorar el silencio.}

Nos parece que la forma en que en los EEUU resuelven la cuestión y que ya hemos descrito, ilustra bien un punto que es central en nuestra manera de ver el problema, esto es, que la posibilidad de que el silencio del imputado cumpla un rol en la decisión del juzgador no depende solo de una norma que permita o prohiba valorarlo. Una norma semejante no tiene sentido en un sistema de jurados donde el razonamiento de los juzgadores no es controlable, y lo que cobra importancia es el contexto en que el silencio se manifiesta o no en la audiencia. En el sistema de los EEUU, no se trata solo de que el fiscal y el juez no pueden plantear inferencias negativas del silencio del imputado, sino de que toda la organización del juicio permite que el silencio del mismo no llame la atención, pase inadvertido, o lo más inadvertido posible, al jurado que ha de decidir. Así, por ejemplo, la organización del juicio pone bajo la responsabilidad del fiscal la presentación de la prueba de cargo y éste no puede, de ningún modo, convocar al imputado, o hacer que el imputado se vea obligado a manifestar su voluntad de no declarar. Cuando llega el turno de la defensa, por su parte, nadie le pregunta al imputado si desea declarar y éste solo lo hara si el defensor lo convoca. Es decir, toda la organización del juicio está concebida para evitar cualquier expectativa sobre la declaración del imputado por parte de los juzgadores. 
En el caso chileno, nos encontramos que todos los juicios se realizan ante jueces profesionales. Los jueces evidentemente saben que el imputado puede tomar el estrado y declarar si quiere. Pero, además, la ritualidad del juicio hace que el primer acto de la audiencia consista en ofrecerle la palabra al imputado para que declare ${ }^{18}$ En la práctica, si éste no desea hacerlo manifiesta que ejercerá su derecho a guardar silencio. Esta ritualidad no hace otra cosa que realzar el hecho de que el imputado ha rehusado dar su versión de los hechos, si es que opta por ese camino. Por otra parte, no está prohibido que el fiscal, por medio de sus preguntas al propio imputado o a otros testigos, llame la atención de los jueces sobre el silencio que el imputado ha guardado en algún momento, o que lo haga en su alegato de clausura.

La posición que defiende el profesor Correa, en el sentido de entender que el uso del silencio del imputado en su contra está y debe estar prohibida en protección de la garantía del derecho a guardar silencio, nos parece que , en la práctica, puede resultar contraria a otras garantías, como son la de la fundamentación del fallo y el derecho a recurrir del mismo.

La cuestión se plantea de la siguiente manera: en el escenario procesal e institucional concreto en el que el juicio oral chileno tiene lugar, esto es frente a jueces profesionales, con una oferta inicial de la palabra al imputado y sin que el fiscal este impedido de referirse a ella, la posibilidad de que la negativa del imputado a dar su versión de los hechos, o de la prueba, tenga un impacto importante en la mente de los jueces es muy alta. Evidentemente esto no será así en todos los casos, pero en algunos si lo tendrá. Imaginemos un caso en el que dado el contenido de la acusación y las pruebas presentadas, resultaría razonable esperar que, si es que el imputado tuviera una explicación alternativa, la diera. Es decir, en un caso sin pruebas directas que muestren a los jueces lo que ocurrió de un modo inequívoco, no obstante, se presentan una serie de pruebas indiciarias que, apreciadas en conjunto, hacen pensar que la única explicación razonable es que las cosas hayan ocurrido del modo que sostiene el fiscal, y que si existiese otra explicación, sería una bastante extraordinaria que, de acuerdo al sentido común, cualquier persona inocente debiera entregar.

Creo que un buen ejemplo del tipo del caso que estamos describiendo se encuentra en el fallo del llamado caso Luchsingüer-Mackay. En el juicio, en el que se condenó al machi Celestino Córdova por el Homicidio 
del matrimonio integrado por el señor Lüchsinger y la señora Mackay, el Ministerio Público presentó pruebas que acreditaron que las víctimas fueron atacadas en su casa rural por un grupo de personas que prendieron fuego a la propiedad, producto del cual las víctimas murieron sofocadas. Además, se probó que durante los hechos el señor Lüchsinger disparó su arma contra los atacantes. Respecto del acusado, testigos dieron cuenta de que éste fue encontrado por el personal policial que acudió al llamado de emergencia, herido en una pierna por una bala del mismo calibre de la pistola disparada por la víctima, a una distancia aproximada de mil quinientos metros del lugar del ataque. ${ }^{19}$ Una vez que llegaron los policías junto con personal de salud, el acusado guardó completo silencio, no entregando explicación alguna sobre su presencia en el lugar, ni sobre su herida y, además, se resistió a la atención médica que se le ofreció por el personal especializado. En el juicio se demostró, además, que la familia Lüchsinger-Mackay había sido objeto de múltiples amenazas y ataques anteriores, aparentemente vinculados a disputas respecto de sus tierras.

Esta versión muy simplificada del caso, da cuenta de una situación en que no existe una prueba directa que vincule al imputado con los hechos. Se trata de un conjunto de circunstancias, su presencia en el lugar y su herida, que hacen pensar que, lo más probable, es que las cosas hayan ocurrido de acuerdo a la versión planteada por la fiscalía. Esto es, que Celestino Córdova haya sido uno de los atacantes de la familia Lüchsinger Mackay, que en ese contexto haya sido herido por los disparos del dueño de casa, que al momento de acudir la policia se encontrara huyendo del lugar, y que se retrasó respecto de sus coautores debido, precisamente, a su herida en la pierna. Es decir, los indicios apuntan claramente hacia la versión del fiscal. ¿Excluyen totalmente otra versión que pueda explicarlos de modo alternativo? No, sería perfectamente posible imaginar otra explicación, por ejemplo, que Córdova se encontraba cazando con un compañero, que éste lo hirió casualmente y lo abandonó en el lugar asustado por la posibilidad de ser castigado, o que Córdova fue asaltado herido por los propios atacantes que huían del lugar después del incendio. Estas dos, y otras explicaciones más, son perfectamente posibles y podrían adquirir plausibilidad durante el juicio, pero requerirían que el imputado las planteara, y sería totalmente razonable que lo hiciera. Si no lo hace, dada la solidez de los indicios en su

19 Sentencia del Tribunal de Juicio Oral en lo Penal de Temuco de 28 de febrero de 2014 dictada en causa Rit No 220-2013 que condenó a Celestino Córdova Tránsito como autor del ataque incendiario que culminó en la muerte del matrimonio Lüchsinger- Mackay. 
contra, su silencio tiende a fortalecer la versión del fiscal, porque la falta de una explicación alternativa tiende a cerrar la posibilidad de una duda razonable.

En este tipo de situaciones, es decir, cuando el imputado es puesto por la prueba de cargo en la posición de tener que dar una explicación, es cuando el silencio puede ser percibido por los jueces como un elemento de corroboración de la prueba de cargo. Este es un razonamiento más o menos obvio que probablemente los jueces harán de cualquier modo. El problema que surge es si ese razonamiento de los jueces que conocen del caso debe ser explicitado en la sentencia, o que dada la existencia de una prohibición de valoración del silencio los jueces no deben mencionarlo, aunque éste forme parte de su reflexión, por la tendencia natural que todos tenemos a usar el sentido común para resolver situaciones complejas.

Si pretendemos que tal razonamiento esté prohibido, podría lograrse que algunos jueces no lo tomen en cuenta, incluso, que algunos abogados no lo invoquen y que todos los jueces lo excluyan de su análisis probatorio. Es probable que algunos jueces ejerciten tal autodisciplina más allá del texto de la sentencia, pero también es muy probable que no todos lo hagan, o que aún haciéndolo, esta falta de explicación de parte del imputado cumpla algún rol, aunque sea ténue, en el aplomo, o en la tranquilidad, con que pronuncian una sentencia condenatoria.

Si queremos, y nos parece completamente deseable que ello ocurra, limitar los abusos de las inferencias negativas extraídas del silencio del imputado, lo que no debemos hacer es prohibir su valoración, a lo menos, en un contexto procesal como el chileno, puesto que, tratándose de una cuestión tan natural en la interpretacion del comportamiento ajeno, a la que estamos habituados en nuestra vida normal, es imposible garantizar por completo que los jueces no la utilicen, especialmente frente a casos complejos en que la decisión se encuentre cerca de los límites entre la absolución o condena.

Por otra parte, los riesgos de un uso abusivo del silencio del imputado son muy claros: su aplicación en casos débiles o cuya fortaleza puede ser cuestionada e, incluso, la posibilidad de que se desarrolle un cierto automatismo en el sentido de asumir que si el imputado no declara, es probable que sea culpable. Todas estas son formas de alteración de la carga de la prueba que pueden también operar como un trasfondo que no se explicita en el fallo y que, consecuentemente, no se puede controlar. 
Por lo tanto, lo razonable es aplicar al silencio del imputado los métodos de control de calidad del razonamiento con los que el sistema cuenta y que consisten en exigir que se expliciten en la sentencia y su examen crítico por medio del recurso de nulidad, de modo que la Corte que lo conoce pueda verificar si su uso es de aquellos consistentes con las garantías básicas, o no lo es.

No contamos con un estudio sistemático de la jurisprudencia de la Corte Suprema en esta materia, pero la lectura de varios fallos que hemos podido identificar da cuenta de una tendencia a rechazar declarativamente la valoración del silencio del imputado, pero al mismo tiempo tolerarla, disminuyendo su importancia cuando el resto de la prueba parece suficientemente sólida.

En un caso ocurrido al inicio de la vigencia del Código Procesal Penal, la Corte Suprema rechazó la nulidad contra un fallo que valoró el uso del silencio del imputado en su contra, en un caso en el que un imputado de robo no dió explicación alguna frente a la existencia de una serie de pruebas circunstanciales de bastante solidez. ${ }^{20}$ En un caso posterior, la Corte negó la nulidad de otro fallo que valoró el silencio a partir de la suficiencia de la prueba restante. ${ }^{21}$

En el Caso Lüchsinger-Mackay la Corte Suprema declaró que del silencio del imputado no se puede valorar en su contra. No obstante, rechazó el recurso de nulidad contra el fallo del tribunal de Temuco que valoró en contra del imputado el conjunto de la actitud del condenado al momento de la detención, negándose a dar alguna explicación y rechazando a la atención médica, silencio que mantuvo durante todo el resto del proceso incluyendo el juicio. De nuevo el argumento fue la suficiencia de la prueba restante. ${ }^{22}$

Más recientemente la Corte Suprema validó el uso del silencio, pero en un sentido muy preciso. Se trata de un caso relativo al artículo 445 del Código Penal que sanciona la posesión de llaves falsas, ganzúas u otros instrumentos destinados a cometer robos, e incluye la exigencia de

20 Sentencia de la Segunda Sala de la Corte Suprema de 19 de diciembre de 2002 en causa ingreso $\mathrm{N}^{\circ} 4.290-2002$ que rechaza el recurso de nulidad deducido por la defensa en contra de la sentencia de 18 de octubre de 2002 del Tribunal de Juicio Oral en lo Penal de Curicó, señalando que no hubo infracción a la presunción de inocencia, ni al derecho a guardar silencio, toda vez que fueron respetados en el juicio y que lo razonado por los jueces se enmarca en el ejercicio propio del debate contradictorio en este tipo de juicios.

21 Por ejemplo, sentencia de la Segunda Sala de la Corte Suprema de 25 de junio de 2012, en causa ingreso $\mathrm{N}^{\circ} 3.521-2012$.

22 Corte Suprema Rol No 6247-14 de 12 de mayo de 2014. 
falta de explicaciones por parte del imputado. La Corte acogió la nulidad por otros motivos, pero validó la exigencia de falta de explicaciones, la que entendió no constituye parte del tipo penal, sino la explicitación del desaprovechamiento por parte del imputado de la oportunidad de explicar su conducta. ${ }^{23}$

Si se mira bien la actitud de la Corte, en la práctica, no parece tan distante de la solución que ha usado el Tribunal Europeo de Derechos Humanos, en el sentido de hacer depender la validez del silencio del imputado de la solidez de la prueba de cargo. La diferencia está en que nuestra Corte parece preferir el rechazo formal, a la valoración del silencio, aunque este último no le molesta, si la prueba es suficientemente fuerte para sustentar la condena.

\section{Conclusiones.}

La cuestión de la valoración del silencio del imputado es una cuestión de enorme importancia en la práctica de nuestro sistema de justicia penal, ella juega un rol en la forma en que los tribunales resuelven algunos casos difíciles, en los que la suficiencia de la prueba está en los límites. Pero, además, condiciona de modo muy determinante la estrategia de los litigantes, tanto fiscales como defensores. Esta estrategia tiene, a su vez, dos manifestaciones principales, una está vinculada a la decisión de defensor de aconsejar a su cliente declarar, o no hacerlo, en cada etapa procesal, y en el caso de los fiscales representa un desafío argumentativo fundamentalmente en el momento de los alegatos de clausura.

La cuestión de la legitimidad de la valoración del silencio es una cuestión que es muy debatida en el derecho comparado y que no ha sido resuelta de forma homogénea por las tradiciones jurídicas más prestigiosas, ni por el derecho internacional de los derechos humanos, en consecuencia, parece razonable que la jurisprudencia y la doctrina chilenas busquen fórmulas que resulten apropiadas a lograr un mejor funcionamiento del sistema y a procurar que no se alteren los principios básicos del sistema por medio de normas o prácticas inapropiadas.

En cuanto a la cuestión del silencio parcial, esto es, a la situación en que el imputado guarda silencio en algún momento del proceso, mientras que declara en otros momentos, nos parece que la valoración racional de las declaraciones prestadas requiere que el tribunal se haga cargo en la 
sentencia del silencio que en otro momento procesal haya guardado el imputado, cuando ese análisis resulta relevante.

Respecto del silencio total, esto es, cuando el imputado no da ninguna versión ni explicación de su comportamiento durante todo el proceso, en el contexto chileno somos de la opinión que, tanto por lo dispuesto en el texto de la ley, como por el modo en que la declaración del imputado está dispuesta en nuestro juicio oral, no debe entenderse que su valoración está prohibida, sino, por el contrario, que está exigida, salvo en los dos casos explícitamente previstos en la ley. El propósito de esta exigencia es el de permitir que, tanto el condenado como el tribunal que conoce del recurso contra la condena, puedan revisar el sentido que los jueces han otorgado al silencio y así poder corregirlo si es que se trata de un uso abusivo, en el sentido de alterar la carga de la prueba en contra del imputado, o de imponer un costo excesivo al ejercicio del derecho a guardar silencio.

La regla contenida en la letra h) del artículo 93 del Código Procesal Penal, constituye, en nuestra opinión, una prohibición de valoración del silencio, pero ella es solo aplicable a las situaciones en que la ley expresamente exige que sea informada al imputado, esto es, ente la policía y en su primera comparecencia ente el fiscal. Por lo tanto, en las otras etapas procesales en las que el imputado puede hacer uso de su derecho a declarar, su silencio puede ser utilizado como fuente de inferencias negativas en su contra por parte de los juzgadores en el fallo.

La valoración del silencio del imputado solo será legítima si se hace de modo consistente con las garantías básicas, esto es, sin alterar la presunción de inocencia en su contra, ni imponiendo al imputado una carga excesiva de prestar declaración que prive a la misma de su carácter autónomo. En consecuencia, las inferencias negativas solo pueden ser obtenidas del silencio cuando la prueba ha sido suficientemente sólida para poner al imputado en la necesidad de tener que dar una explicación de su conducta. Es la solidez de la prueba la que limita la ambigüedad del silencio del imputado y lo puede constituir en un indicio válido que reafirme una culpabilidad demostrada por otros medios. 


\section{Bibliografía.}

AYER, Donald: "The Fifth Amendment and the Inference of guilt form silence: Griffin v California after Fifteen Years”. En: Michigan Law Review, Vol 78, № 6 (may, 1980). Págs. 841-871.

ASCENCIO, Jose María: "El derecho al silencio del imputado”. En: Revista Digital de la Maestría en Ciencias Penales, Número 9. Año 9, 2017.

CORREA, Carlos: "Valoración del silencio del imputado en el proceso penal. Derecho alemán y derecho chileno". En: Revista de Derecho, Vol. 31, No 2, octubre 2018. Págs. 237-261.

KUSANOVIC, Marcos: El uso del silencio del acusado en el juicio oral, su alcance y valoración en la jurisprudencia chilena. Tesis de Magíster en Derechos Penal y Procesal Penal Universidad Diego Portales, 2016.

MORALES, Oscar: "El poder de las costumbres ¿requiem por el derecho a guardar silencio?”. En: Actualidad Jurídica Uria Mendez, № 36, 2014. Págs. 53-67.

O'REILLY, Gregory: "Limits the Rigth to Silence and Moves Towards an Inquisitorial System of Justice". En: Journal of Criminal Law and Criminology, Volume 85, Issue 2, 1994. Págs. 402-452.

ROOK SNYDER, Barbara: "A Due Process Analysis of the Impeachment Use of Silence in Criminal Trials". En: William and Mary Law Review, volume 29, issue 2, 1988. Págs. 285-340. 